\title{
BMJ Open Changes in the type and amount of spending disclosed by Australian pharmaceutical companies: an observational study
}

\author{
Lisa Parker, Emily A Karanges, Lisa Bero
}

To cite: Parker L, Karanges EA, Bero L. Changes in the type and amount of spending disclosed by Australian pharmaceutical companies: an observational study. BMJ Open 2019:9:e024928. doi:10.1136/ bmjopen-2018-024928

- Prepublication history and additional material for this paper are available online. To view these files, please visit the journal online (http://dx.doi. org/10.1136/bmjopen-2018024928).

Received 21 June 2018

Revised 21 November 2018

Accepted 23 November 2018

Check for updates

(C) Author(s) (or their employer(s)) 2019. Re-use permitted under CC BY-NC. No commercial re-use. See rights and permissions. Published by BMJ.

School of Pharmacy Faculty of Medicine \& Health, The University of Sydney Charles Perkins Centre, Sydney, New South Wales, Australia

Correspondence to

Dr Lisa Parker;

lisa.parker@sydney.edu.au

\section{ABSTRACT}

Objectives To describe and quantify disclosed payments from the pharmaceutical industry to the healthcare sector, and to examine the impact of the 2015 changes to Australia's self-regulated system of transparency.

Design Observational database study.

Setting Australia.

Participants Publicly available reports submitted by members of Australian pharmaceutical industry trade organisations, Medicines Australia and the Generic and Biosimilar Medicines Association (GBMA) (October 2011December 2017).

Exposure Changes to transparency reporting requirements with the updates of pharmaceutical industry Codes of Conduct in 2015.

Main outcome measures Elements of healthcare sector spending that members of industry organisations are required to publicly disclose; cumulative amount of disclosed spending (monthly average) in the year prior to and following the revision.

Results There was a $34.1 \%$ reduction in disclosed spending from Medicines Australia member companies in the year after the 2015 changes to the Code of Conduct were introduced (\$A89 658566 in the preceding year, October 2014-September 2015; \$A59 052551 in the following year). The new Code allowed for reduced reporting of spending on food and beverages at events and for sponsored healthcare professionals. However, there was enhanced transparency around identification of individual health professionals receiving payments. GBMA member reporting totalled \$A2 580402 in the year prior to the revision, then ceased.

Conclusions This study shows the limitations of a selfregulatory system around industry disclosure of spending. We advocate for robust regulatory systems, such as legislation, to promote mandatory long-lasting public transparency.

\section{INTRODUCTION}

Financial relationships between healthcare professionals and the pharmaceutical industry influence healthcare. ${ }^{12}$ Exposure of healthcare professionals to the pharmaceutical industry is widespread, ${ }^{3}$ but the financial details and extent of these relationships
Strengths and limitations of this study

- We compiled and analysed over 900 transparency reports on pharmaceutical industry payments to the Australian healthcare sector, including payments to medical practitioners and other healthcare professionals, third parties such as medical organisations and hospitals, and health consumer groups.

- We identified key changes in the industry's self-regulatory codes regarding transparency reporting, and examined changes in disclosed spending occurring concurrently with these changes; our analysis could not determine causality.

- We relied on information provided by pharmaceutical companies in their transparency reports and did not verify the accuracy or completeness of the data.

- Only member companies of Australia's pharmaceutical industry trade organisations are required to submit transparency reports; therefore, our data do not reflect total spending and changes in membership status may affect disclosed payments.

may be unclear. The USA and some European countries have legislated mandatory reporting of payments from pharmaceutical and medical device manufacturers to healthcare professionals, ${ }^{4}$ and Ontario, Canada has recently introduced similar legislation. ${ }^{5}$ Other jurisdictions rely on self-regulation governed by industry associations such as the European Federation of Pharmaceutical Industries and Associations. ${ }^{6}$

Australia has previously been at the forefront of transparency reporting. ${ }^{7}$ For example, the pharmaceutical industry trade association Medicines Australia introduced a self-regulatory transparency programme over a decade ago, when its 2007 Code of Conduct required member companies to publicly report their spending on educational events for healthcare professionals. ${ }^{8}$ Importantly, this included spending for 'educational' events attended by healthcare professionals from many disciplines, including nurses, pharmacists, 
physiotherapists and dietitians, as well as medical practitioners. The Generic and Biosimilar Medicines Association (GBMA), formerly the Generic Medicines Industry Association, introduced a similar requirement for its members in 2010, although this became non-compulsory in 2013. ${ }^{9}$ The GBMA also requested that members report 'non-price benefits' to pharmacists, including, for example, provision of training, pharmacy aids, merchandising, software and vouchers.

In 2015, after pressure from the Australian Competition and Consumer Commission, Medicines Australia amended its Code to require public reporting of the amounts paid to individual, identified healthcare professionals. At the same time, however, the requirements to

Table 1 Description of required reporting categories from Medicines Australia and GBMA members

Report category Dates reported Description Payments reported

Medicines Australia reports

Educational July 2007- Payments related to educational

events for September 2015* events for HCPs that are held by

healthcare the company or a third party (eg,

professionals hospital, medical organisation).

Fees to HCPs for services at events (eg, speaking, chairing).

Sponsorship to HCPs to cover costs of event attendance (eg, registration, travel, accommodation, food and beverages). Event running costs (eg, venue hire, food and beverages).

$\begin{array}{llll}\text { Healthcare } & \text { January 2013- } & \text { Payments to HCPs for consultancy Consultant fees and associated costs (eg, travel, } \\ \text { professional } & \text { September 2015 } & \begin{array}{l}\text { services. } \\ \text { accommodation, food and beverages). }\end{array}\end{array}$
consultants September 2015 services. accommodation, food and beverages).

Advisory board January 2013- Payments to HCPs contracted to Advisory board participation fees. participation September 2015 provide advice to the company as part of an advisory board.

Board meeting running costs (eg, food and beverages; venue hire; costs associated with HCP attendance including travel, accommodation, food and beverages).

$\begin{array}{lll}\begin{array}{l}\text { Health } \\ \text { consumer } \\ \text { organisation } \\ \text { support }\end{array} & \begin{array}{l}\text { January 2013- } \\ \text { ongoing }\end{array} & \begin{array}{l}\text { Support to not-for-profit } \\ \text { organisations representing the } \\ \text { interests of health consumers. }\end{array} \\ \begin{array}{l}\text { Third-party } \\ \text { meeting } \\ \text { sponsorship }\end{array} & \begin{array}{l}\text { October 2015- } \\ \text { ongoing }\end{array} & \begin{array}{l}\text { Payments related to educational } \\ \text { events for HCPs that are held by } \\ \text { a third party (eg, hospital, medical } \\ \text { organisation). }\end{array}\end{array}$
Financial and non-financial support (eg, for events, activities, publications).

Fees to HCPs for services at third-party events (eg, speaking, chairing).

Sponsorship to HCPs to cover costs of attendance at third-party events (eg, registration, travel, accommodation). $\dagger$

Event running costs (eg, venue hire, food and beverages). $\neq$

$\begin{array}{llll}\begin{array}{l}\text { Payments to } \\ \text { healthcare }\end{array} & \begin{array}{l}\text { October 2015- } \\ \text { ongoing }\end{array} & \begin{array}{l}\text { Payments to individual, identified } \\ \text { HCPs for providing advice or other consultancy, speaking or chairing at events). }\end{array} \\ \begin{array}{ll}\text { professionals } \\ \text { services or to attend educational } \\ \text { events. } \$\end{array} & \begin{array}{l}\text { Sponsorship to HCPs to cover costs of attendance } \\ \text { at events (registration, travel, accommodation). }\end{array}\end{array}$

\section{GBMA reports}

$\begin{array}{llll}\begin{array}{l}\text { Educational } \\ \text { events }\end{array} & \begin{array}{l}\text { April 2010-June } \\ 2015^{*}\end{array} & \begin{array}{l}\text { Payments related to educational } \\ \text { events for HCPs that are held by } \\ \text { the company or a third party (eg, } \\ \text { hospital, medical organisation). }\end{array} & \begin{array}{l}\text { Fees to HCPs for services at events (eg, speaking, } \\ \text { chairing). } \\ \text { Sponsorship to HCPs to cover costs of } \\ \text { event attendance (eg, registration, travel, } \\ \text { accommodation, food and beverages). } \\ \text { Event running costs (eg, venue hire, food and } \\ \text { beverages). }\end{array} \\ \begin{array}{l}\text { Non-price } \\ \text { benefits to }\end{array} & \begin{array}{l}\text { December 2010- } \\ \text { June } 2015^{*}\end{array} & \begin{array}{l}\text { Sales incentives provided to } \\ \text { pharmacists. }\end{array} & \begin{array}{l}\text { For example, pharmacy aids, merchandising, } \\ \text { vouchers, access to training opportunities. }\end{array}\end{array}$

pharmacists

*Data presented from October 2011.

†Travel includes airfares only; excludes ground transfers, taxis and parking.

¥Reporting is not required if food and beverages are the company's only contribution to the event.

§Prior to 1 October 2016, disclosure of an HCP's identifying information was contingent on the consent of the HCPs. All payments received by non-consenting HCPs were reported in aggregated format.

GBMA, Generic and Biosimilar Medicines Association; HCP, healthcare professional. 


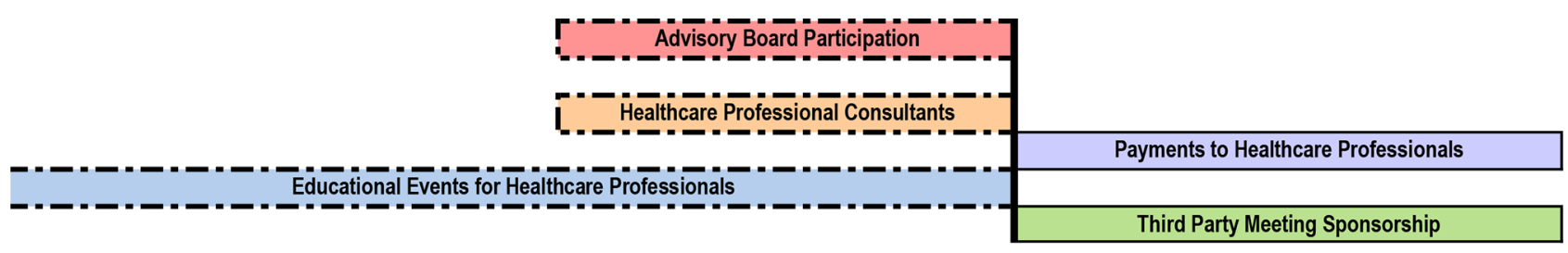

Health Consumer Organisation Support

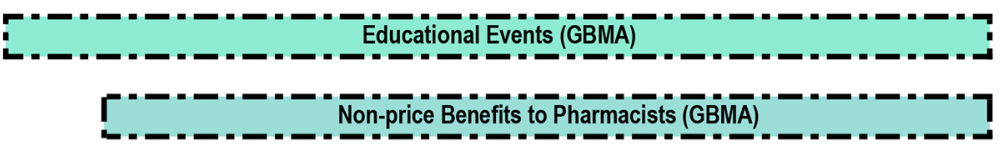

$\begin{array}{lllllllll}2010 & 2011 & 2012 & 2013 & 2014 & 2015 & 2016 & 2017 & 2018\end{array}$

Figure 1 Timeline of required reporting by Medicines Australia and Generic and Biosimilar Medicines Association (GBMA) members according to industry-defined categories (see table 1 for further information). Dates are approximate only. Educational events disclosures started July 2007. Payments to healthcare professionals category are a partial merger (with some exclusions) of three former categories: healthcare professional consultants, advisory board participation and educational events. The thirdparty educational events category is a subset of the former educational events category.

report on spending for educational events were watered down. ${ }^{10}$ The GBMA followed suit, noting that 'Medicines Australia has removed this requirement [for educational event reporting] of its members', and citing the 'significant compliance burden placed on members' and the 'consistently demonstrated...appropriate conduct over the past 5years' as further reasons to remove these reports on spending (p6). ${ }^{11}$ Unlike Medicines Australia, the GBMA did not introduce any requirements to report spending to individual healthcare professionals, educational events run by third parties or consumer groups. These transparency losses were criticised at the time. ${ }^{12}$ The objective of this paper is to describe changes in the types of spending disclosed and cumulative amount of spending following the 2015 changes in industry-regulated reporting requirements. We highlight exactly what information has been lost and gained from the public record in Australia, and report on the financial changes.

\section{METHODS}

We conducted an observational study of publicly available reports submitted by members of Australian pharmaceutical industry trade organisations, Medicines Australia and the GBMA (October 2011-December 2017).

Details on current and previous Medicines Australia and GBMA reporting requirements are available through their respective websites: https://medicinesaustralia. com.au/ and https://www.gbma.com.au/. We used the relevant Codes and related documents associated with the current ${ }^{10}$ and previous ${ }^{13}$ Medicines Australia Codes of Conduct, and the current ${ }^{11}$ and previous ${ }^{14}$ GBMA Codes of Practice, to identify changes to transparency information required from organisation members.

\section{Data sources and analysis}

Transparency reports on Medicines Australia and GBMA member company spending are available through the respective industry body websites as separate reports (usually PDF files) for each company, reporting period and report category. Our research group has previously downloaded and compiled Medicines Australia reports on educational events for healthcare professionals (October 2011-September 2015; reports prior to October 2011 are no longer publicly accessible) and payments to healthcare professionals (May 2016-April 2017), converting them into databases for research purposes and public use. ${ }^{67}$ These data are publicly available for download: https://researchdata.sydney.edu.au/index.php/s/npni79P4NhVQ0XB and https://research-data.sydney.edu.au/index.php/s/ 0MmrflPyiQrf53a, respectively. The current project extends on this work by updating these pre-existing databases and compiling additional databases from more recent reports downloaded from Medicines Australia and GBMA. In total, this project employed 905 Medicines Australia reports (October 2011-December 2017) collated into six distinct databases according to the report categories defined by Medicines Australia. Specifically, these databases contain reports on payments related to (1) educational events for healthcare professionals (October 2011-September 2015); (2) healthcare professional consultants (January 2013September 2015); (3) advisory board participation (January 2013-September 2015); (4) health consumer organisation support (January 2013-December 2017); (5) third-party meeting sponsorship (October 2015-October 2017); and (6) payments to healthcare professionals (October 2015-October 2017). We generated two databases from the 64 available GBMA reports detailing GBMA member payments related to (1) educational events (for healthcare professionals) and (2) non-price benefits to pharmacists (see table 1 for a description of each category and figure 1 for a timeline of available reports). Further information about each report category is provided in online supplementary files 1 and 2 .

We identified 39 Medicines Australia members filing transparency reports in the year preceding the changes to their reporting requirements (October 2014-September 
2015), compared with 34 in the following year (October 2015-September 2016). There were five GBMA members filing transparency reports in the most recent period for which reports were requested by their industry body (ie, ending June 2015), compared with none in the following year and since.

Due to the aggregate nature of many reports, we calculated the cumulative expenditure in each category as a monthly average over the given reporting period. Change in total expenditure from Medicines Australia and GBMA member companies over time was used to assess the impact of changes in reporting requirements in October 2015 and July 2015, respectively.

\section{Patient or public involvement}

No patients or members of the public were involved in this study.

\section{RESULTS}

The 2015 changes to the Medicines Australia Code resulted in merging and crossover of pre-existing reporting categories, as well as inclusion of some new elements and discontinuation of others. For example, information formerly captured in the educational events database is now reported in the third-party and healthcare professional databases. The main required reporting elements in the old and new Medicines Australia Codes of Conduct are listed in table 2, with further details in online supplementary files 1 and 2 . The transparency gains and losses from Medicines Australia and GBMA members are summarised in table 3.

In the year preceding the 2015 changes to the Medicines Australia Code, industry payments disclosed by Medicines Australia members totalled \$A89 658566 (October 2014-September 2015) across four reporting

Table 2 Types of payments publicly reported by Medicines Australia members before and after the change to reporting requirements in October 2015

\begin{tabular}{|c|c|c|}
\hline & $\begin{array}{l}\text { Pre-October } \\
2015\end{array}$ & $\begin{array}{l}\text { Post-October } \\
2015\end{array}$ \\
\hline \multicolumn{3}{|l|}{ Payments to HCP consultants* } \\
\hline Fees for provision of services & $\checkmark$ & $\checkmark$ \\
\hline Sponsorship of HCP for educational event attendance (travel, accommodation) & $\checkmark$ & $\sqrt{ } \S$ \\
\hline Sponsorship of HCP for educational event attendance (food and beverages) & $\checkmark$ & \\
\hline \multicolumn{3}{|l|}{ Payments related to company-run educational events and advisory boards $\dagger$} \\
\hline Fees for provision of services (eg, speaking, chairing, advisory board participation) & $\checkmark$ & $\checkmark$ \\
\hline Event registration costs & $\checkmark$ & $\checkmark$ \\
\hline Sponsorship of HCP for educational event and meeting attendance (travel, accommodation) & $\checkmark$ & $\sqrt{ } \S$ \\
\hline Sponsorship of HCP for educational event and meeting attendance (food and beverages) & $\checkmark$ & \\
\hline Food and beverages at meeting & $\checkmark$ & \\
\hline Event running costs (eg, venue hire, event organiser, trade displays) & $\checkmark$ & \\
\hline \multicolumn{3}{|l|}{ Payments related to third-party (independent) educational eventsł } \\
\hline Fees for provision of services (eg, speaking, chairing) & $\checkmark$ & $\checkmark$ \\
\hline Event registration costs & $\checkmark$ & $\checkmark$ \\
\hline Sponsorship of HCP for meeting attendance (travel, accommodation) & $\checkmark$ & $\sqrt{ } \S$ \\
\hline Sponsorship of HCP for meeting attendance (food and beverages) & $\checkmark$ & \\
\hline Food and beverages at event & $\checkmark$ & $\sqrt{9}$ \\
\hline Other event costs (eg, venue hire, event organiser, trade displays) & $\checkmark$ & $\checkmark$ \\
\hline \multicolumn{3}{|l|}{ Payments to health consumer organisations ${ }^{* *}$} \\
\hline Sponsorship, trade displays for consumer events & $\checkmark$ & $\checkmark$ \\
\hline Other (eg, publications) & $\checkmark$ & $\checkmark$ \\
\hline
\end{tabular}

${ }^{*}$ Captured in the HCP consultants reports (pre-2015) and HCP reports (post-2015).

†Captured in the educational events and advisory board reports (pre-2015) and HCP reports (post-2015).

‡Captured in the educational events reports (pre-2015), and third-party and HCP reports (post-2015).

$\S$ Travel includes airfares only, excludes ground transfers, taxis and parking.

IReporting is not required if food and beverages are the company's only contribution to the event.

${ }^{\star *}$ Captured in the health consumer organisation reports (pre-2015 and post-2015).

$\mathrm{HCP}$, healthcare professional. 
Table 3 Summary of gains and loss in current Medicines Australia and GBMA reports compared with pre-2015 reports

\begin{tabular}{ll}
\hline Gains & Losses \\
\hline $\begin{array}{l}\text { Identification of healthcare } \\
\text { professionals receiving }\end{array}$ & Spending from Medicines Australia member companies associated with: \\
payments from Medicines & Food and beverages and small travel costs (taxis, ground transfers) to sponsored HCPs \\
$\begin{array}{ll}\text { Australia member companies } \\
\text { for provision of services }\end{array}$ & Event running costs (eg, venue hire, event organiser, food and beverages for industry-run \\
$\begin{array}{l}\text { or sponsorship for event } \\
\text { attendance (registration costs, } \\
\text { travel, accommodation). }\end{array}$ & events and advisory board meetings). \\
& Food and beverages served at third-party events where no other sponsorship was \\
& for pharmacists.
\end{tabular}

GBMA, Generic and Biosimilar Medicines Association; HCP, healthcare professional.

categories. Reported payments included \$A74 264438 $(82.8 \%)$ on educational events run by the company or third party, \$A8 $743250(9.8 \%)$ on health consumer organisation support, \$A4 $158819(4.6 \%)$ on costs associated with advisory board participation, and \$A2 492059 $(2.8 \%)$ on healthcare professional consultants.

In the year following the 2015 change, reported payments from Medicines Australia members totalled \$A59 205301 (October 2015-September 2016), an overall reduction of $34.1 \%$. Payments reported in the new categories, healthcare professional reports and third-party educational events, totalled \$A30 380145 and \$A20 364929 respectively. There was little change in the total reported expenditure on health consumer organisation support (\$A8 461228 ), which was the only reporting category to remain unchanged in the revised code (see figure 2). Excluding payments associated with this category, there was a $37.3 \%$ reduction in disclosed Medicines Australia payments. As shown in table 2 the reduction in disclosed payments coincides with loss of information about spending on running costs for industry-run events and meetings (including food and beverages), and hospitality to sponsored healthcare professionals attending events and meetings.

In the year preceding the 2015 changes to the GBMA Code, industry payments disclosed by GBMA members totalled \$A2 580402 (July 2014-June 2015). Of these reported payments, $88.3 \%$ were for non-price benefits to pharmacists and the remainder were for educational events. After July 2015, \$A0 payments have been reported by GBMA members, a drop of $100 \%$.

\section{DISCUSSION}

Recent changes to Australian self-regulatory codes have delivered gains in disclosure of recipient identities but an overall reduction in transparency around industry funding in the healthcare sector. Dropping the requirements for transparency around items such as expenditure on food and beverages means that over a third of previously reported industry spending on healthcare professionals is now hidden. In addition, the new Code failed to include other disclosures about industry interactions with health professionals that countries such as the UK and USA have introduced, such as pharmaceutical company spending on free drug samples and funding for research. ${ }^{6}$ The changes have also added an extra layer of complexity to what is already difficult-to-understand data on disclosed payments. This complexity hinders transparency.

This erosion of transparency has taken place in a time of increasing societal interest in disclosure.

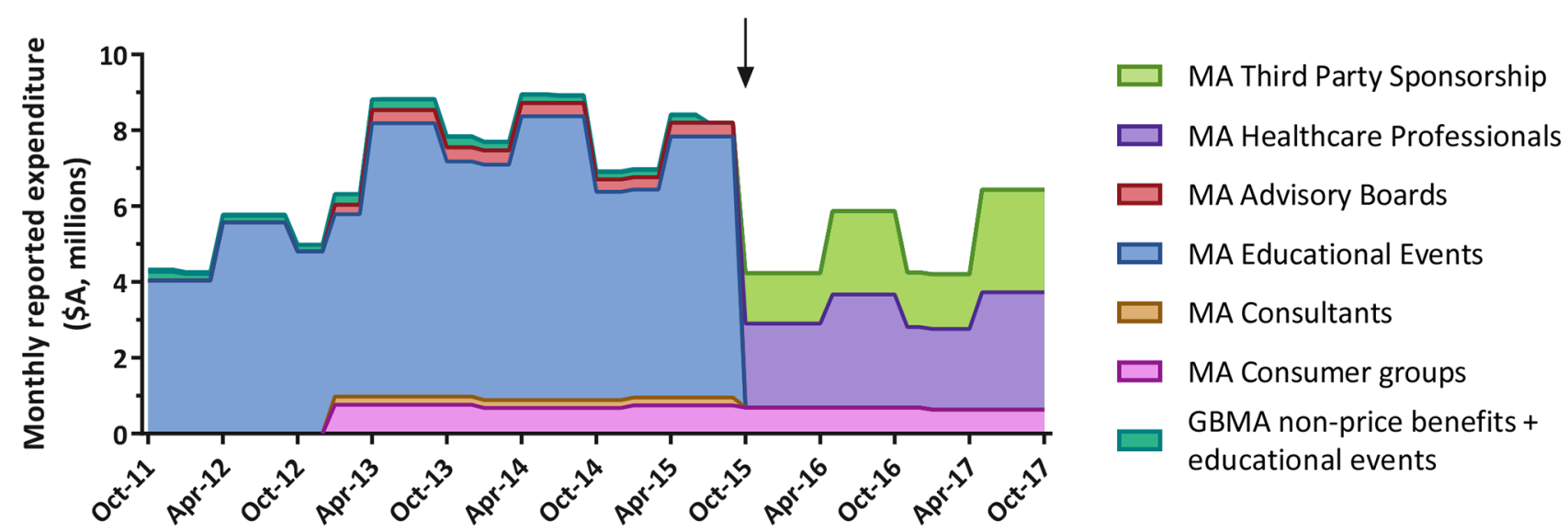

Figure 2 Cumulative monthly expenditure disclosed in transparency reports from Medicines Australia (MA) and Generic and Biosimilar Medicines Association (GBMA) members. The arrow indicates date of change to Medicines Australia reporting requirements. 
Transparency around pharmaceutical industry spending in the healthcare sector is important for several reasons. First, the public have a legitimate expectation that all transfers of value between the pharmaceutical industry and the healthcare sector will be available for scrutiny in order to assess and judge the appropriateness of such interactions. Second, transparency may assist those reading or receiving the disclosure to judge the risk of bias in those making the disclosure. For example, disclosures of competing interests by research authors make academic readers more critical of an article. ${ }^{15}$ However, authors who disclose conflicts of interest are more likely to exaggerate their claims, ${ }^{16}$ and even critical readers tend not to sufficiently discount the credibility of biased information sources, so the audience may still take home a biased message. ${ }^{17}$

Third, transparency requirements may change the behaviour of those making the disclosure. In situations where disclosures are required or expected, individuals may avoid accepting payments in order to avoid making the declaration ${ }^{18}$ and the same may apply to corporations. For example, if the industry is required to declare costs associated with food and beverage provision at third-party events such as medical grand rounds and journal clubs, they may be less likely to provide this kind of sponsorship. While healthcare professionals may be disappointed at the reduction in 'free' lunches, this change would reduce industry influence on healthcare, because receipt of industry-sponsored meals, even low-cost meals, increases prescribing of the brand-name drug being promoted at the time. ${ }^{1}$

The erosion of organisational transparency that we document in the paper is particularly significant. Although disclosure is a burden for the pharmaceutical industry, organisational transparency has the advantage of not relying on disclosures from individual healthcare professionals. These disclosures are potentially counterproductive since patients may feel extra pressure to follow the advice of those who declare conflicts of interests, in order to avoid implying distrust of their practitioner. ${ }^{1619}$ Dropping organisational disclosure of food and beverage spending also seems to send the wrong message to potential recipients, that is, that this transfer of value is not significant enough to warrant reporting. As a result, healthcare professionals may be more likely to participate in industry-sponsored lunches.

Transparency is unlikely to be a complete solution to concerns about commercial influence within the healthcare sector. ${ }^{20}$ There are many other important elements involved in managing this issue, including, for example, the prohibition of clinical trials that seek to familiarise prescribers with new medications rather than add to scientific knowledge (so-called 'seeding trials'), honorary authorships for healthcare professionals and the release of free drug samples into clinic rooms. ${ }^{21}$ However transparency is a necessary first step towards assessing and analysing the level of industry influence, and may act as a deterrent to inappropriate interactions between individual professionals and industry.

Self-regulated transparency programmes may avoid the usual checks and balances of a more formal regulatory system, and in the case described here self-regulation has allowed the pharmaceutical industry to make changes associated with significant reductions in disclosed spending. Self-regulated transparency enables voluntary reporting, as in the early stages of the Medicines Australia programme. It also fails to regulate companies that are not members of the relevant industry body. We advocate for legal mandating of comprehensive transparency about industry sponsorship in an effort to minimise loss of transparency data in ways such as we report on here. In this particular case, we recommend that the Australian Government introduce transparency legislation. We recommend new legislation that maintains the current Medicines Australia transparency focus around spending on healthcare professionals and health consumer groups, and extends this requirement to include all companies in the pharmaceutical and medical device sector including GBMA members and companies with no affiliation to trade organisations. We propose mandatory disclosure on spending on drug samples and research. We also recommend that legislation should reinstate previously compulsory reporting of aggregated food, beverages and venue costs at company-run educational events and advisory board meetings, and food and beverages provided to healthcare professionals where costs per head are over a minimum amount as required by the US legislation.

\section{Limitations}

The calculated amount of industry spending in the healthcare sector for both the pre-2015 and post-2015 periods may be an underestimate. There are companies that are not members of Medicines Australia or GBMA and hence do not disclose their spending. In addition, compliance with the GBMA Code was not compulsory for GBMA members from $2013,{ }^{22}$ so the true pre-2015 spending figure is likely to have been higher than our calculated figure. There may be inaccuracies in the spending disclosed by the companies in the original reports: we could not verify the accuracy and completeness of the data, but many companies do provide independent audits of their reports. The reduction in Medicines Australia member companies submitting reports, from 39 in the year prior to the change in reporting requirements to 34 after the change, contributed to the reduction in the cumulative disclosed sum, although was unlikely to have had a big impact. Together, these five companies only disclosed a total of \$A4 199674 between October 2014 and September 2015, which was $4.68 \%$ of the total disclosure by all companies over this period. Finally, our results cannot prove a causal relationship between changing industry Codes and cumulative disclosed spending. We think it is likely that current spending 
remains similar to 2015 levels, and that the apparent reduction in cumulative spending is due to changed reporting patterns. It is possible, however, that cumulative spending may have truly decreased as a result of the changes in reporting and/or other requirements introduced in the new Code (eg, introduction of a $\$ 120$ limit per head on meals for healthcare professionals), or that reductions in spending may reflect a move towards alternative methods of promotion to healthcare professionals not captured by the previous or current transparency programme. Finally, as mentioned above, the programme of required reporting is complex, and changes are difficult to follow. There may be some elements that we have misinterpreted.

Once a leader in transparency, Australia is now falling behind other countries. This study provides a clear example of the limitations of a self-regulatory system, which can be quietly changed in such a way as to reduce overall public reporting of industry funding in the healthcare sector. We recommend that countries insist on legislation rather than self-regulation to promote long-lasting public transparency around industry spending.

Acknowledgements We thank S Swandari and A Fabbri for their contributions to building the database of disclosed payments from publicly accessible industry documents.

Contributors All authors conceived of the study. LP wrote the first and subsequent drafts. EAK extracted and analysed the data, prepared the tables, and critically revised the manuscript. LB participated in creating the original database and critically revised the manuscript. All authors reviewed and approved the final manuscript.

Funding The authors have not declared a specific grant for this research from any funding agency in the public, commercial or not-for-profit sectors.

Competing interests None declared.

Patient consent for publication Not required.

Ethics approval Not required.

Provenance and peer review Not commissioned; externally peer reviewed.

Data sharing statement Limited data from this study are publicly available. Data on pharmaceutical industry-funded events for Australian health professionals (October 2011-September 2015) are available at https://research-data.sydney. edu.au/index.php/s/npni79P4NhVQ0XB. The pharmaceutical industry payments to healthcare professionals (May 2016-April 2017) database is available at https://research-data.sydney.edu.au/index.php/s/OMmrfIPyiQrf53a. Neither of these available databases currently include all educational events for healthcare professionals reports or payments to healthcare professional reports included in this manuscript. The complete health consumer organisation database (January 2013-December 2016) is available at https://researchdata.ands.org.au/ pharmaceutical-industry-funding-december-2016/1330638.

Open access This is an open access article distributed in accordance with the Creative Commons Attribution Non Commercial (CC BY-NC 4.0) license, which permits others to distribute, remix, adapt, build upon this work non-commercially, and license their derivative works on different terms, provided the original work is properly cited, appropriate credit is given, any changes made indicated, and the use is non-commercial. See: http://creativecommons.org/licenses/by-nc/4.0/.

\section{REFERENCES}

1. DeJong C, Aguilar T, Tseng CW, et al. Pharmaceutical IndustrySponsored Meals and Physician Prescribing Patterns for Medicare Beneficiaries. JAMA Intern Med 2016;176:1114-10.

2. Yeh JS, Franklin JM, Avorn J, et al. Association of Industry Payments to Physicians With the Prescribing of Brand-name Statins in Massachusetts. JAMA Intern Med 2016;176:763-8.

3. Fabbri A, Grundy Q, Mintzes B, et al. A cross-sectional analysis of pharmaceutical industry-funded events for health professionals in Australia. BMJ Open 2017;7:e016701.

4. Ia Santos A. The sun shines on Europe: transparency of financial relationships in the healthcare sector. The Netherlands: Health Action International, 2017.

5. ServiceOntario. Health Sector Payment Transparency Act, 2017 New Regulation. Ontario's Regulatory Registry. 2018 http://www. ontariocanada.com/registry/view.do?postingld=26846\&language $=e n$.

6. Fabbri A, Santos A, Mezinska S, et al. Sunshine Policies and Murky Shadows in Europe: Disclosure of Pharmaceutical Industry Payments to Health Professionals in Nine European Countries. Int $J$ Health Policy Manag 2018;7:504-9.

7. Robertson J, Moynihan R, Walkom E, et al. Mandatory disclosure of pharmaceutical industry-funded events for health professionals. PLoS Med 2009;6:e1000128.

8. Medicines Australia. Code of Conduct. $15^{\text {th }}$ edn. Australia: ACT: Medicines, 2007. https://medicinesaustralia.com.au/code-ofconduct/code-of-conduct-current-edition/archived-codes-ofconduct/. (accessed 1 Feb 2018).

9. Generic Medicines Industry Association. Code Administration Committee Report Operation of GMiA Code of Practice. $2011 \mathrm{https} / / /$ www.gbma.com.au/wp-content/uploads/2013/01/Review-GMiACode-Oct-2011-Final.pdf (accessed 19 Apr2018).

10. Medicines Australia. Code of Conduct. $18^{\text {th }}$ edn. Australia: ACT: Medicines, 2015. www.medicinesaustralia.com.au/code-of-conduct/ code-of-conduct-current-edition. (accessed 1 Feb 2018).

11. Generic and Biosimilar Medicines Association. Code of Practice. 4th ed. NSW: Australia, 2015. https://www.gbma.com.au/wp-content/ uploads/2013/01/GBMA_Code_4thEdition_Final_160202.pdf. (accessed 1 Feb 1 2018).

12. Vitry A. Transparency is good, independence from pharmaceutical industry is better!. Aust Prescr 2016;39:112-3.

13. Medicines Australia. Archived Codes of Conduct ACT: Medicines Australia, 2018. https://medicinesaustralia.com.au/code-of-conduct/ code-of-conduct-current-edition/archived-codes-of-conduct/. (accessed 10 Apr 2018).

14. Generic and Biosimilar Medicines Association. GBMA Code of Practice: Annual reviews NSW. Australia: GBMA, 2018. https://www. gbma.com.au/gmia-code-of-practice/annual-review/. (accessed 19 Apr 2018).

15. Chaudhry S, Schroter S, Smith R, et al. Does declaration of competing interests affect readers' perceptions? A randomised trial. BMJ 2002;325:1391-2.

16. Loewenstein G, Sah S, Cain DM. The unintended consequences of conflict of interest disclosure. JAMA 2012;307:669-70.

17. Silverman GK, Loewenstein GF, Anderson BL, et al. Failure to discount for conflict of interest when evaluating medical literature: a randomised trial of physicians. J Med Ethics 2010;36:265-70.

18. Sah S, Loewenstein G. Nothing to declare: mandatory and voluntary disclosure leads advisors to avoid conflicts of interest. Psychol Sci 2014;25:575-84.

19. Sah S, Loewenstein G, Cain DM. The burden of disclosure: increased compliance with distrusted advice. J Pers Soc Psychol 2013;104:289-304

20. Grundy Q, Habibi R, Shnier A, et al. Decoding disclosure: Comparing conflict of interest policy among the United States, France, and Australia. Health Policy 2018;122:509-18.

21. Parker $L$, Williams $J$, Bero $L$. Ethical drug marketing criteria for the 21st century. BMJ 2018;361:k1809.

22. Generic and Biosimilar Medicines Association. Code of Practice Annual Review NSW. Australia: GBMA, 2013. https://www.gbma. com.au/gmia-code-of-practice/annual-review/. (accessed 10 Apr2018) 